\title{
Information structure in interaction: conditional clauses i DR's Debatten
}

\section{LAURA BANG LINDEGAARD AND LINE SANDST}

In this article, we investigate conditional clauses in argumentative interaction. In Danish, conditional clauses usually begin with if and can be defined as clauses where a sufficient condition for a given matter is stated. The data consists of transcripts of four different episodes of the national Danish television-broadcasting corporation DR's Debatten, and the study thus focuses on polemical, argumentative debate interaction. Based on previous studies of conditional clauses in Danish, we investigate both the host's and participants' use of conditional clauses and positive and negative meaning in these sentences. In doing so, we investigate how the participants and the host use value-laden conditional clauses as a rhetorical resource in the argumentative context. The study contributes with knowledge about conditional clauses related to the genre of 'argumentative TV debate', which is a context where the use of conditional clauses has not yet been thoroughly investigated in Danish.

KEYWORDS: conditional clauses; argumentation; valorization; affect; TV debate interaction 